\title{
THE PHOTOGRAPHIC EMULSION: SILVER ION AND HYDROGEN ION CONCENTRATIONS AND SENSI- TIVITY
}

\author{
By Burt H. Carroll and Donald Hubbard
}

ABSTRACT

The paper is introduced by discussions of previous experimental and theoretical work on silver and hydrogen ion concentrations in emulsions, and description of experimental technique. These variables are taken up first according to their effects on afterripening, and second according to their direct effects on sensitivity when changes in afterripening are eliminated (in experiments after digestion). The rate of afterripening increases with increasing silver ion concentration and increasing $\mathrm{pH}$; the corresponding effects on sensitivity are much larger than those produced by the direct effect of environment (after digestion). The combination of silver ion with gelatin reduces the effect of excess silver. Illustrations are given for the distribution of excess bromide or silver in the emulsion with changing $\mathrm{pH}$. The desensitizing action of bromide (after digestion) is found to increase with increasing acidity; conversely, the effect of $\mathrm{pH}$ is dependent on the silver ion concentration. Spectral sensitivity of the emulsions is found to be independent of hydrogen or silver ion concentrations; these variables must, therefore, influence sensitivity through secondary reactions in latent image formation. Results are discussed in terms of a new concept of the adsorption of gelatin to silver bromide, based on the "zwitterion" theory of ampholytes.

\section{CONTENTS}

I. Introduction

II. Review of literature

III. Experimental technique

IV. Hydrogen ion-silver ion-gelatin equilibrium and its effects on sensitivity

1. Adjustments before digestion

(a) Hydrogen ion concentration, with varying time of digestion.--_-_-

(b) Hydrogen and silver ion concentrations with constant time of digestion....

2. Adjustments after digestion
(a) Silver ion concentration at constant $\mathrm{pH} \mathrm{H}_{-}$

(b) Hydrogen ion concentration.

V. Discussion

\section{INTRODUCTION}

It has long been common knowledge that the photochemical sensitivity of silver halides is increased by the presence of soluble silver salts. The effect of acidity or alkalinity has been less clearly recognized, but early work on both these variables in silver bromide-gelatin emulsions is to be found in Eder's Handbuch. ${ }^{1}$ While these variables must always be studied by using acids or alkalies in one case, and soluble silver salts or bromides in the other, it is now recognized that the results of experiments upon the effects of acids and bases may most frequently be generalized by considering the resulting concentration 
(or activity) of the hydrogen ion which is the common variable in all such experiments. In silver bromide emulsions, the effects of adding silver salts or bromides may similarly be expressed in terms of the resulting silver ion concentrations. In aqueous solutions the concentrations of hydrogen and hydroxyl ions may always be expressed by the relation $\left[\mathrm{H}^{+}\right] \times\left[\mathrm{OH}^{-}\right]=10^{-14}$. Similarly, in silver bromide emulsions, at $30^{\circ}$ C., $\left[\mathrm{Ag}^{+}\right] \times\left[\mathrm{Br}^{-}\right]=9.2 \times 10^{-13}$. The solubility product of silver bromide here plays a part analogous to the dissociation product of water, since the enormous available surface of the highly disperse silver bromide insures that the emulsion may at all times be considered saturated with respect to this salt. The silver ion concentration may be determined by the potential of the silversilver bromide electrode exactly as the hydrogen ion concentration is determined by the hydrogen electrode. It is also possible to express the results in terms of the excess of one material or another which is present, but as gelatin combines both with hydrogen ions and silver ions, ${ }^{2}$ the relations of the chemical composition to the ion concentrations may be quite complicated. Data on these relations of chemical composition to ion concentrations will be given in this paper, but we will in general discuss the results in terms of the ion concentrations. As just explained, silver ion and bromide ion concentrations are interrelated like hydrogen ion and hydroxyl ion concentrations and either may be used to specify a given condition. The silver ion-gelatin combination being dependent on the hydrogen ion concentration, the silver ion and hydrogen ion concentrations of an emulsion are not entirely independent variables and are, therefore, treated together in this paper.

The relation of any variable to sensitivity of photographic emulsions changes with the stage of emulsion making which is under consideration. We shall deal in this paper only with the effects on the washed emulsion, omitting the ripening process before washing. Even with this limitation of scope it seems necessary to distinguish between two possible mechanisms. In the first place, both silver and hydrogen ion concentrations of an emulsion during digestion will influence sensitivity through the rate of afterripening; $\mathrm{we}^{3}$ have previously given considerable data on the effect of silver ion concentration on afterripening, and preliminary results on hydrogen ion concentration. In the second place, there may be an effect caused directly by the existence of a given hydrogen or silver ion concentration in the emulsion at the time of exposure. Sheppard and Wightman ${ }^{4}$ have referred to this as the effect of environment on sensitivity; they do not specifically define the term, but we infer that it means the thermodynamic environment of the silver halide grains, and we shall use it in that sense. The effect of environment might a priori be expected to be reversible; that is, on reproducing a given set of conditions, the corresponding sensitivity should also be reproduced. The afterripening process is, in contrast, irreversible, but obviously both effects must be superimposed when the hydrogen ion concentration of an emulsion is changed before afterripening.

This paper presents data on afterripening under a wide range of both hydrogen and silver ion concentrations, and on the relation of sensi-

2 Carroll and Hubbard, B. S. Jour. Research, vol. 7 (RP376), p. 811, 1931.

8 Carroll and Hubbard, B. S. Jour. Research, vol. 7 (RP340), p. 219, 1931.

- Sheppard and Wightman, Phot. J., vol. 69, p. 22, 1929. 
tivity to these variables under conditions such that the afterripening effect has been eliminated. Similar experiments with emulsions containing sensitizing dyes will be reported in a separate communication.

\section{REVIEW OF LITERATURE}

We are indebted to Rawling and his associates ${ }^{5}$ at the British Photographic Research Association for the first quantitative studies of the effect of the hydrogen ion concentration of emulsions on their sensitivity. In many of their experiments the $\mathrm{pH}$ of portions of the emulsion was adjusted to the desired value (by addition of acid or alkali) during or after washing, and the total effect measured after the separate portions were digested "to equilibrium." In another series they changed the $\mathrm{pH}$ of emulsions two or more times during digestion, coating test plates after each change, and found that the sensitivity changed immediately with the change of the hydrogen ion concentration and returned to its original value (corrected for the slow continuous increase due to afterripening) when the original $\mathrm{pH}$ was restored. Rawling refers to this latter as the "reversible effect," as distinguished from the slow "irreversible effect" of afterripening. The ratio of speed at two values of $\mathrm{pH}$ was found to be independent of emulsion formula, of grain size within the emulsion, or of the presence of nuclei derived from sulphur sensitizers, but was dependent on the gelatin. Fog and the shape of the characteristic curve were also reported to be independent of the $\mathrm{pH}$ during afterripening, and no extension of spectral sensitivity to longer wave lengths was detected.

While the emulsions in the earlier papers are described as "digested to equilibrium," the curves in the 1929 paper indicate that at the higher $\mathrm{pH}$ the afterripening was still progressing slowly during the experiments. At $\mathrm{pH} 5$ the afterripening stopped entirely, and there was even a slight decrease in sensitivity in some cases.

Sheppard and Wightman ${ }^{6}$ confirmed Rawling's observation of a reversible change in sensitivity when the $\mathrm{pH}$ of liquid emulsions was changed before coating. They found that some irreversible process occurs on drying, since the sensitivity of dried plates was not affected by immersing them in buffer solutions ranging from $\mathrm{pH} 3$ to 11 . Their data in some cases show a distinct increase in fog with $\mathrm{pH}$.

There has been little quantitative work dealing with the effect of silver ion concentration on sensitivity. Sheppard and Wightman ${ }^{7}$ demonstrated that sensitivity is appreciably reduced by the presence of $0.001 \mathrm{~N}$ soluble bromide, the effect increasing with concentration. Control experiments proved that the results could not be explained by action of the bromide on the latent image or by absorption of light by its solution. In dilute solutions at least, sensitivity was restored by washing out the bromide before exposure. When plates were exposed under $0.01 \mathrm{~N}$ silver-nitrate solution, acidified to $\mathrm{pH} 4$, and the silver removed before development (by washing with dilute acid), there was no effect on sensitivity.

Fajans and his students ${ }^{8}$ have investigated the effect of adsorbed ions on the sensitivity of silver bromide. As their experiments dealt

5 Rawling and Glassett, Phot. J., vol. 66, p. 495, 1926. Rawling and Vick, Phot. J., vol. 67, p. $42,1927$. Rawling, Phot. J., vol. 69, p. 83, 1929. Rawling, Proc. 7th Internat. Cong. Photography (London), p. $192,1928$.

See footnote 4, p. 482.

7 Sheppard and Wightman, Phot. J., vol. 69, p. 134, 1929.

Summary in Lüppo-Cramer, Grundlagen der Phot. Negativverfahren, p. 633. 
with the photolysis of colloid-free material, extension of their results to developable sensitivity in emulsions must be justified by experiment. They found that silver bromide with adsorbed bromide ions had the same spectral sensitivity as pure material, the threshhold being at about $430 \mathrm{~m} \mu$. Adsorbed silver or hydroxyl ions extended the spectral sensitivity to at least $615 \mathrm{~m} \mu$; careful measurements detected a corresponding change in spectral absorption, although the increase in rate of photolysis was much greater than the increase in absorbed energy under the same conditions. Fajans attributes the effects of the adsorbed ions to deformation of the outer electron shells of the surface bromide ions in the silver bromide by electrostatic attraction, which facilitates the transfer of electrons from bromide to silver ions. Luppo-Cramer ${ }^{9}$ tested for the existence of this effect in silver bromide-gelatin emulsions by bathing them in dilute $\mathrm{NH}_{4} \mathrm{OH}$ or $\mathrm{NaOH}$ solutions, washing, and drying. Plates thus treated were blackened by light without development much more rapidly than before treatment; their sensitivity to red light with development was also increased, but the sensitivity to white light with development was little affected. Factors other than adsorbed hydroxyl ions may have entered into these results.

Various hypotheses have been offered to explain the effect of hydrogen ion concentration on sensitivity, especially the reversible effect.

Slater Price ${ }^{10}$ has described experiments by Rawling and Owens which show that the rate of reaction of gelatin with hypochlorite or hypobromite increases with increasing $\mathrm{pH}$. The equilibrium in the solutions shifts with increasing $\mathrm{pH}$ toward the $\mathrm{OCl}^{-}$or $\mathrm{OBr}^{-}$ ions, which are apparently the reactive forms. This indicates that the $\mathrm{pH}$ effect on sensitivity may be explained by change in the rate of reaction between the gelatin and the bromine liberated on exposure. A serious difficulty is introduced by the quantitative agreement between the reactivity of three samples of gelatin, although the photographic effect of $\mathrm{pH}$ is rarely the same for two different samples of gelatin. However, the conditions chosen for study of the reaction appear to have been unsuitable for the detection of such differences. In the illustrative data the weight of available chlorine in the hypochlorite solution was slightly greater than the weight of gelatin, corresponding to a very large chemical excess; in the curve of Figure 1, the gelatin had absorbed up to 6 per cent of its weight of chlorine. In view of the very small quantity of bromine liberated in the formation of the latent image, it seems as though differences between samples of gelatin might be more obvious in experiments where the gelatin was in great excess and only the earliest stages of the reaction were studied.

Gramse ${ }^{11}$ has also used the hypothesis of reaction between the gelatin and bromine liberated by photolysis as a factor in the formation of the latent image. He demonstrated experimentally that the rate of reaction between bromine and gelatin increases with increasing $\mathrm{pH}$, explaining this by the formation of hydrobromic acid, which retards the reaction unless taken up by alkali. He also offers the suggestion that since iodine or sulphur can act as halogen carriers in this reaction, the effect of silver iodide or sulphide on sensitivity may be explained in terms of this function. 
Calzavara ${ }^{12}$ has recently suggested that the effect of $\mathrm{pH}$ on sensitivity may be explained in terms of its effect on oxidation-reduction potential, but has apparently not given any experimental evidence in support.

In a speculative paper ${ }^{13}$ Sheppard has suggested that adsorption of gelatin to silver halides takes place at azine linkages which are in equilibrium with heterocyclic ring structures not capable of similar oriented adsorption. As the equilibrium between the dif-

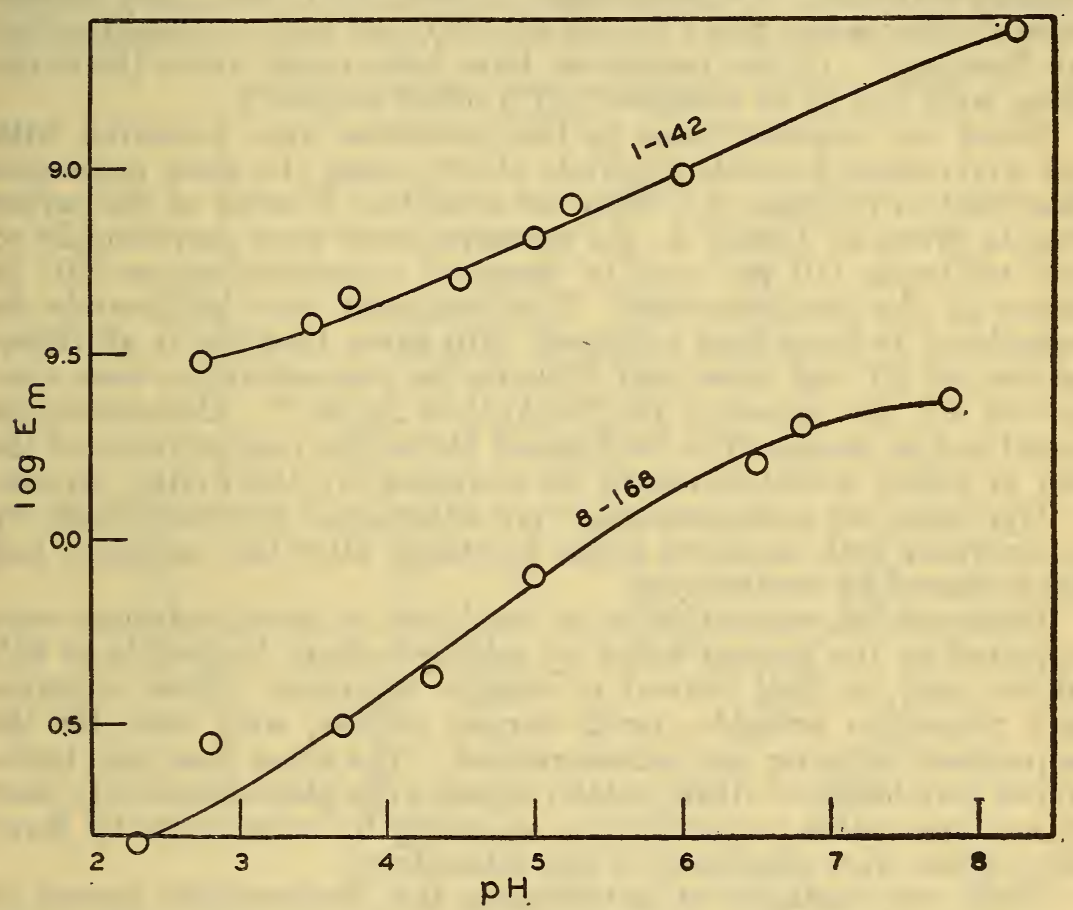

FIgURE 1.-Variation in sensitivity of emulsions with $p H$ during digestion for constant time

ferent conditions of the nitrogen would be dependent on the hydrogen ion concentration, this might affect sensitivity through changes in the protective action of the gelatin.

\section{EXPERIMENTAL TECHNIQUE}

The methods of emulsion making and sensitometry in use in the photographic emulsion laboratory of the Bureau of Standards have recently ${ }^{14}$ been described in detail in connection with our communication on afterripening. We shall here use the same letters to designate the type emulsion formulas given in detail in that paper.

12 Calzavara, Sci. et Ind. Phot. (2), vol. 2, p. 472, 1931.

13 Sheppard, Phot. J., vol. 69 , p. $330,1929$.

14 See footnote 3 , p. 482 
There has been one change in the methods of emulsion making. During the period of most of the experiments on afterripening, the Potomac River, which is the source of the Washington water supply, was very low and clear as the result of drought, being fed largely by springs in limestone formations. The quality of the water was, therefore, quite constant. Since January, 1931, surface water has made up a much larger proportion of the flow and the quality is less reliable; tests indicate the presence of traces of sensitizing and fogging materials. Emulsions since March, 1931, have been washed with distilled water plus $1 \frac{11}{4} \mathrm{~g} \mathrm{MgSO}_{4} .7 \mathrm{H}_{2} \mathrm{O}$ per liter, as recommended by Rawling. ${ }^{15}$ (A few exceptions have been made where the emulsions were not to be compared with other batches.)

Silver ion concentrations in the emulsions were measured with the silver-silver bromide electrode at $30^{\circ}$, using the same apparatus described in reference 2. With the exception of some of the earlier results given in Figure 3, the measurements were reproducible to \pm 2 millivolts ( 10 per cent in terms of concentration, or 0.03 in terms of the ion exponent). The emulsions may legitimately be considered to have been saturated with silver bromide at all times, so that at $30^{\circ}$ the silver and bromide ion concentrations were connected by the equation $\left[\mathrm{Br}^{-}\right] \times\left[\mathrm{Ag}^{+}\right]=9.2 \times 10^{-13}$. Concentrations could not be measured in the finished plates; the concentration of the ion in excess would obviously be increased by the drying process.

Hydrogen ion concentrations were determined colorimetrically by comparison with standard buffer solutions, after the emulsions had been cleared by centrifuging.

Hydrogen ion concentrations of emulsions or gelatin solutions were adjusted to the desired value by adding sodium hydroxide or sulphuric acid, in half normal or weaker solutions. Silver sulphate and potassium bromide, tenth normal or less, were used for the adjustment of silver ion concentrations. The other ions thus introduced (sulphate and alkali metals) appear to be photographically inert in any reasonable concentrations according to experiments by Rawling, which were confirmed in this laboratory.

While our methods of determining the characteristic curves of experimental emulsions were unchanged, the expression of the sensitivity in numerical terms has been altered in some cases. We have continued to use the speed number derived from inertia where a series of emulsions had satisfactory straight lines in their characteristic curves, and could be compared at the same $\gamma$. In following changes such as those occurring during afterripening, where both speed and contrast increase, it was found more satisfactory to use the speed number derived from minimum useful gradient, which appears to express the change in effective sensitivity better than any other single number. A minimum gradient of 0.2 for 6 -minute development was normally used, but on some of the steeper curves a higher value could be read more accurately and appeared better to represent the results judged from the entire curve. 


\section{HYDROGEN ION-SILVER ION-GELATIN EQUILIBRIUM AND ITS EFFECTS ON SENSITIVITY}

\section{ADJUSTMENTS BEFORE DIGESTION}

(a) HYDROGEN ION CONCENTRATION, WITH VARYING TIME OF DIGESTION

When the $\mathrm{pH}$ of an emulsion is adjusted before digestion, and the sensitivity determined after constant time and temperature of digestion, both the reversible effect on sensitivity and the effect on rate of afterripening are involved in the final result. We have given a few illustrations of this case in Tables 17 and 18 of reference 3 . Similar

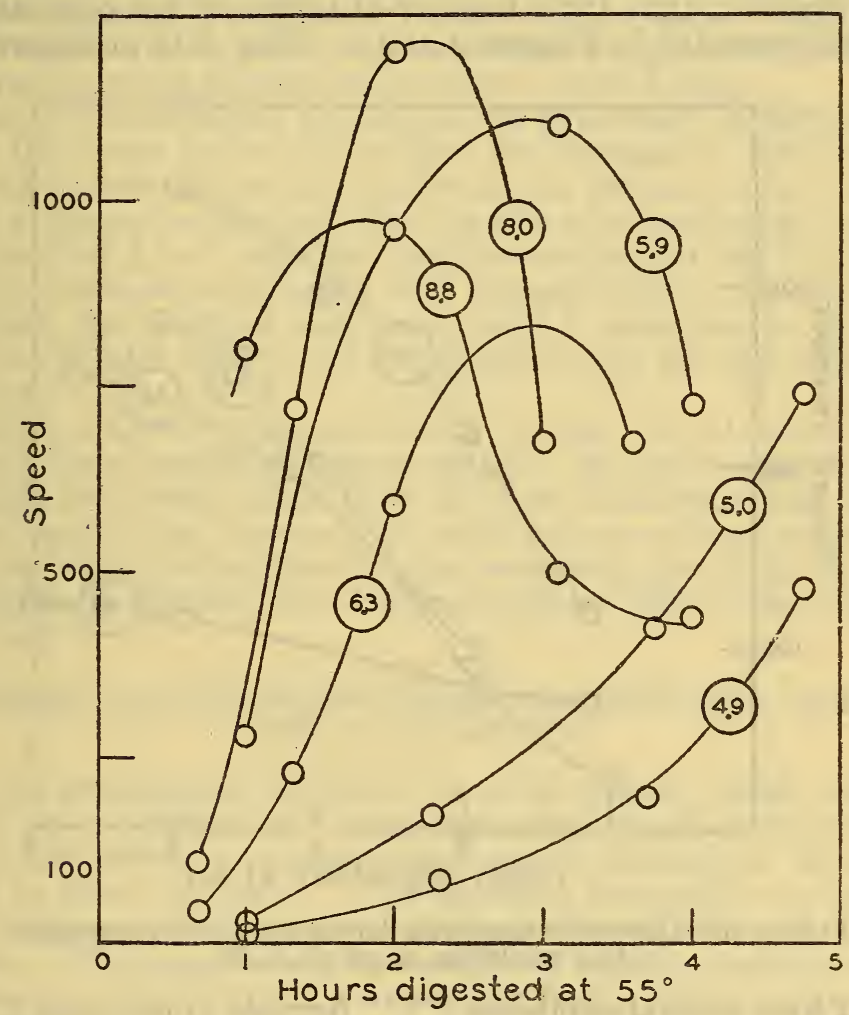

FrgdRe 2.-Changes in sensitivity during digestion for neutral type emulsions at varying $p H$

data covering a wider range of $\mathrm{pH}$ are given in Figure 1 of this paper; the different portions of the emulsions were adjusted in $\mathrm{pH}$, then all digested for two hours at $45^{\circ}$. Both emulsions were of the ammonia type. Bromide ion concentrations in 8-168 varied with $\mathrm{pH}$ from 3 to $12 \times 10^{-5}$; in 1-142 they were not determined, but were probably about one-fifth these amounts. In these emulsions there was a distinct minimum of contrast around the isoelectric point. The variation in sensitivity was most conveniently represented by the exposure required for a given minimum gradient. In this case it was necessary to use a gradient of 0.5 on the curve for 12 minutes development, which was least affected by the pH. Plotting the 
logarithm of this exposure against $\mathrm{pH}$, the curves are approximately linear in both cases; that is, the change in sensitivity was roughly constant for unit change of hydrogen in concentration. The slope of the curve for $8-168$ is larger, which may be ascribed to its greater bromide ion concentration; as previously explained in reference 3, page 240 , this increased slope is to be expected because higher bromide ion concentrations are less affected by $\mathrm{pH}$ so that the true $\mathrm{pH}$ effect is less opposed by increasing $\left[\mathrm{Ag}^{+}\right]$.

The results of comparison on a constant time of digestion were given because this condition might be encountered in practice. More complete information was obtained from curves of sensitivity against digestion time for a number of hydrogen ion concentrations. These are presented in Figures 2 and 3 . The data in Figure 2 were

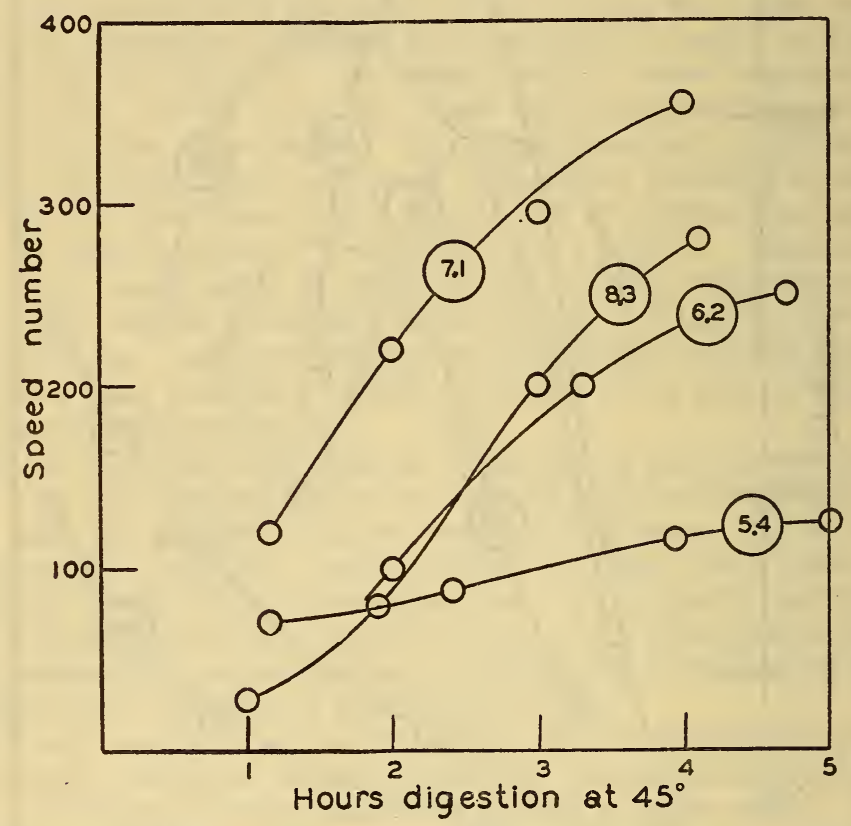

FIGURE 3.-Changes in sensitivity during digestion for ammonia type emulsions at varying $p H$

obtained from neutral emulsions (" $\mathrm{C}$ " formula in reference $3, \mathrm{p} .227$, using 4 per cent AgI, 25 per cent excess $\mathrm{NH}_{4} \mathrm{Br}$ and 25 -minute mixing time at $65^{\circ}$ ). These were all made from the same batch of washed gelatin, and washed with distilled water; the $\mathrm{pH}$ of the emulsions was 4.9 as washed, and was adjusted before digestion by addition of $\mathrm{NaOH}$. Bromide ion concentrations were all within the range 6.5 to $13 \times 10^{-4} \mathrm{~N}$. Sensitivity is represented by the speed calculated as the reciprocal of exposure for minimum useful gradient, in this case the standard value of 0.2 gradient for 6-minute development. The data in Figure 3 were obtained from ammonia process emulsions ("A" formula in reference 3, p. 226, with 5 per cent AgI); these were made from untreated gelatin and washed with distilled water. The $\mathrm{pH}$ as washed was 8.3 ; it was adjusted before digestion by addition of $\mathrm{H}_{2} \mathrm{SO}_{4}$. Bromide ion concentrations were within the range 6.5 to $9.0 \times 10^{-4} \mathrm{~N}$. 
It was found unusually difficult to reproduce results in these experiments. However, it is evident that the rate of afterripening increased rapidly with increasing $\mathrm{pH}$ between 5 and 7 . The increase in rate is greater than the increase in maximum sensitivity, so that it is not merely the result of the reversible $\mathrm{pH}$ effect which would increase sensitivity at all stages of ripening.

In both series of emulsions there was a decrease in maximum sensitivity for $\mathrm{pH}>8$, with no indication of a decrease in rate of afterripening. In the neutral emulsions, there was serious fog at $\mathrm{pH} 8$ or higher; one batch digested at 9.7 was completely ruined. The $\mathrm{NaOH}$ used for adjustment of $\mathrm{pH}$ was tested for the presence of fogging impurities by neutralizing a portion of it larger than used for adjustment and adding this to a portion of emulsion during afterripening at pH 7.3; there was no increase in fog over a control batch.

The fog in the ammonia emulsions was practically independent of $\mathrm{pH}$ over the range 5.4 to 8.3 , so that the decrease in sensitivity at $\mathrm{pH}>8$ in this case can not be ascribed to the increase in fog. On the available evidence we may say that the rate of afterripening increases rapidly from $\mathrm{pH} 5$ to 7 , and that the time required to reach maximum sensitivity decreases continually with increasing $\mathrm{pH}$. At alkalinities greater than the practical maximum, $\mathrm{pH} 8.5$, deterioration is rapid, and may be greater than would be expected from the increased tendency to fog.

The effect of silver ion concentration on the rate of afterripening has already been described in some detail. ${ }^{16}$ In contrast to the effect of hydrogen ion, which alters both the rate of afterripening and the maximum sensitivity, increased bromide ion concentration may only decrease the rate of afterripening, the sensitivity for optimum digestion being little affected up to concentrations higher than those in common use.

\section{(b) HYDROGEN AND SILVER ION CONCENTRATIONS WITH CONSTANT} TIME OF DIGESTION

Since the combination of silver ion with gelatin varies with the hydrogen ion concentration, ${ }^{17}$ any adjustment of $\mathrm{pH}$ involves also a change of free silver ion concentration and in bromide or silver ions adsorbed to silver bromide. It is therefore impossible to give the effects of silver and hydrogen ions on sensitivity distinct and separate treatments. We present first the results of varying both silver and hydrogen ion concentrations in emulsions before afterripening them by digestion.

All four emulsions were made by the following formula:

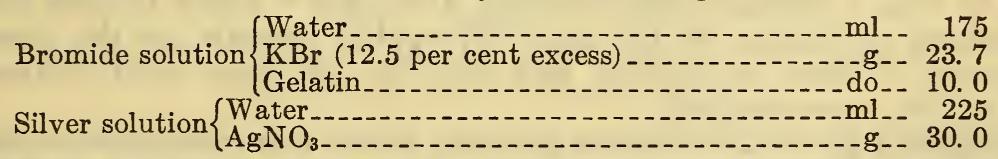

The silver solution was added to the bromide solution in 6 to 7 minutes at $65.0^{\circ} \pm 0.2^{\circ}$. Centrifugal washing, ${ }^{18}$ in three batches, was started at 9 to 10 minutes from the start of mixing and finished at 36 to 38 minutes. The silver bromide was resuspended in $400 \mathrm{ml}$ of

18 Carroll and Hubbard, J. Phys. Chem. vol. 31, p. 910, 1927. 
1 per cent gelatin, at a $\mathrm{pH}$ of $4.7-4.9$. Two batches of this size were then combined, and the silver ion concentration adjusted by appropriate additions of silver sulphate solution; the suspension was then divided into eight $100 \mathrm{ml}$ portions, and left in the refrigerator over night. The next day the separate portions were carefully remelted as needed, centrifuged again, and the final emulsion made by suspension of the silver bromide in $12.5 \mathrm{~g}$ gelatin and $235 \mathrm{ml}$ water. The $\mathrm{pH}$ of the eight batches of emulsion was adjusted by additions of sulphuric acid and each was digested for two hours at $45^{\circ}$. In order to reduce fog in the batches with higher silver ion concentrations, gelatin which had been treated with ammonia and thoroughly washed was used for emulsifying the silver bromide after centrifuging. Pure bromide emulsions made with this partly deactivated material

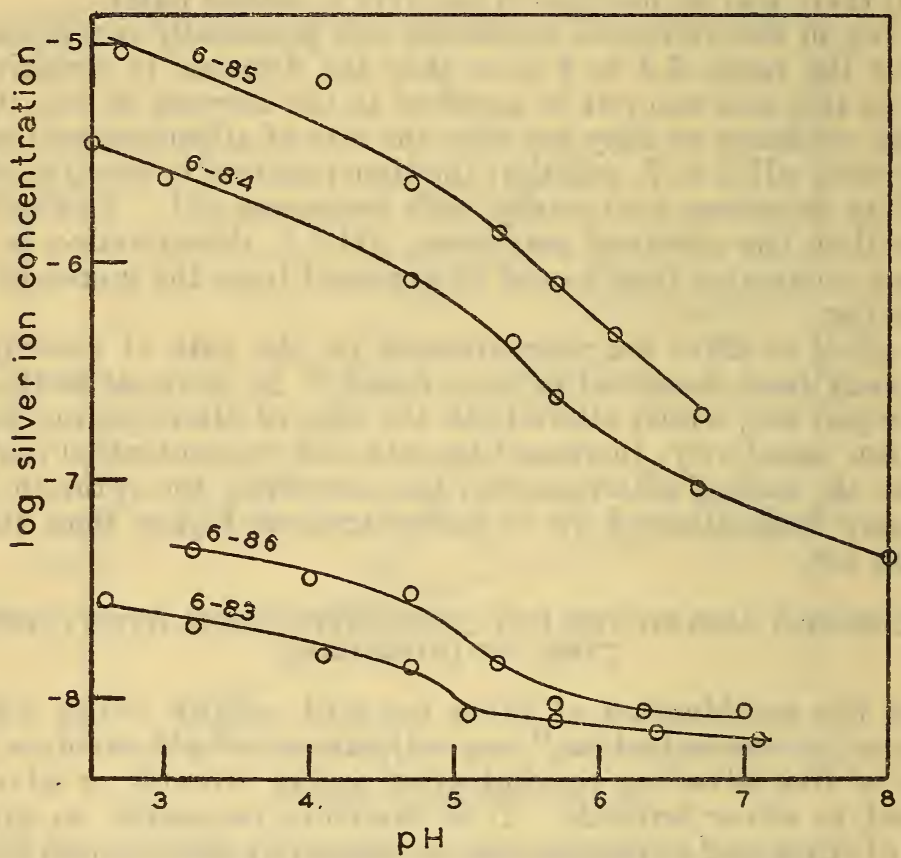

FIgURE 4.-Variation of silver ion concentration of emulsions

necessarily had relatively low sensitivity. Sensitometric tests were made with a special $p$-aminophenol developer ${ }^{19}$ found to give speed numbers equivalent to the usual pyrogallol formula on the normal batches of these emulsions, and less fog on those with increased silver ion concentration.

Figure 4 gives the relation between silver and hydrogen ion concentrations in these emulsions. Silver ion concentrations in the first resuspensions, which determine the range of silver ion concentrations in the final emulsions, were as follows:

\footnotetext{
10 Formula:

p-aminophenol hydrochloride $\mathrm{Na}_{2} \mathrm{SO}_{3}$

$\mathrm{Na}_{2} \mathrm{CO}_{3}$

$\mathrm{KBr}$

Water to make
}

2,4 , and 8 minutes brush development at $20^{\circ} \mathrm{O}$. 
TABLE 1

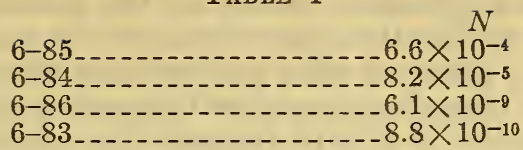

It is evident that the slope of the curves is greater at higher silver ion concentrations. This is readily predicted from the data in reference 2 on the combination of silver ion and gelatin; silver combined with unit weight of gelatin becomes increasingly dependent on $\mathrm{pH}$ at

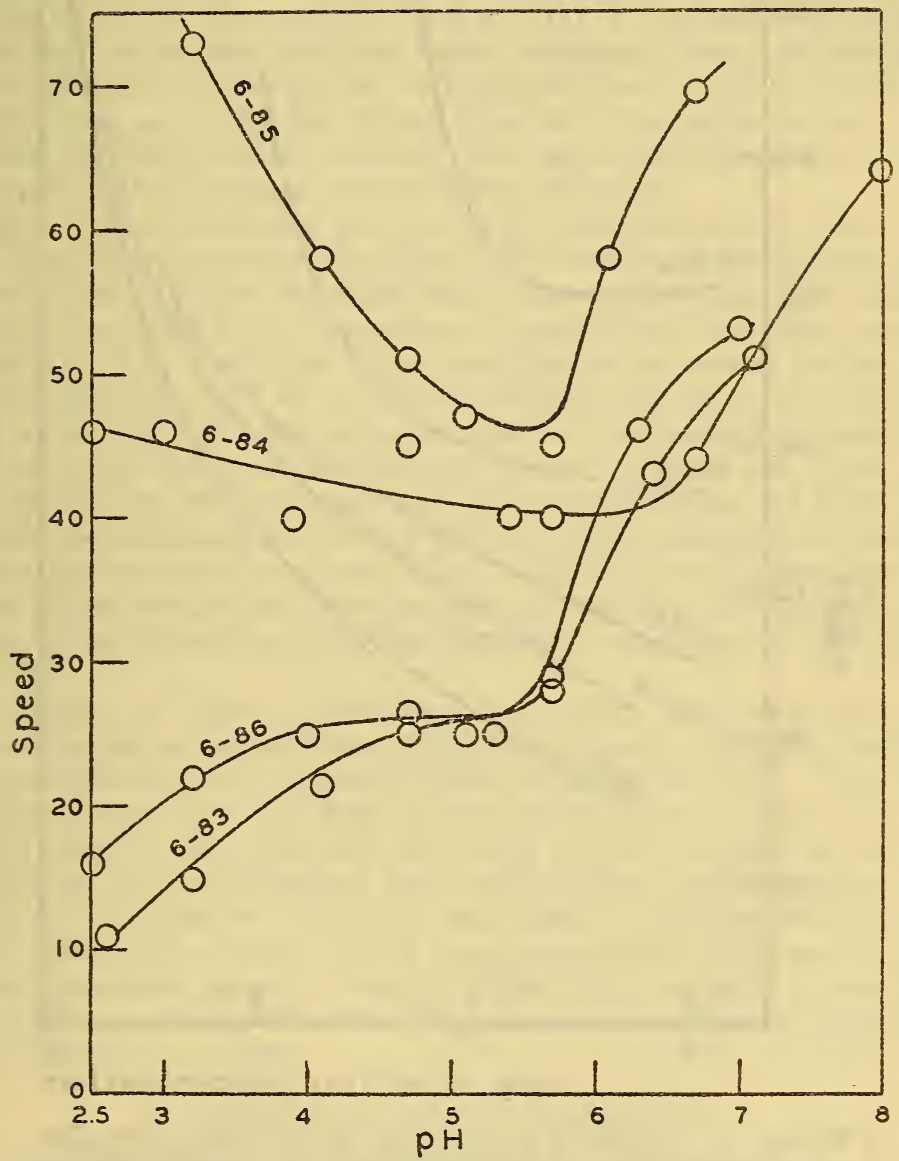

FIGURE 5.-Variation of sensitivity of emulsions with $p H$ during digestion, for constant time of digestion

higher silver ion concentrations. The concentration of free silver ions is therefore more affected under these conditions by the change in combined silver with varying $\mathrm{pH}$. It will further be noted that although the curves show an appreciable break at the isoelectric point of gelatin, they are essentially continuous.

In Figure 5, speeds of these same emulsions are plotted against $\mathrm{pH}$. For these emulsions, speed is expressed as the reciprocal of the expos- 
ure necessary for a gradient of 0.3 at the maximum development time; while there were satisfactory straight line portions of the characteristic curves, $\gamma$ changed with $\mathrm{pH}$, so that the speed from inertia alone was not the best single number expressing sensitivity. Within the normal range of $\mathrm{pH}$ ( 5.5 or higher) the sensitivity for constant' digestion time in each curve shows the usual rapid increase with increasing $\mathrm{pH}$. Comparing the four curves, it increases with increas-

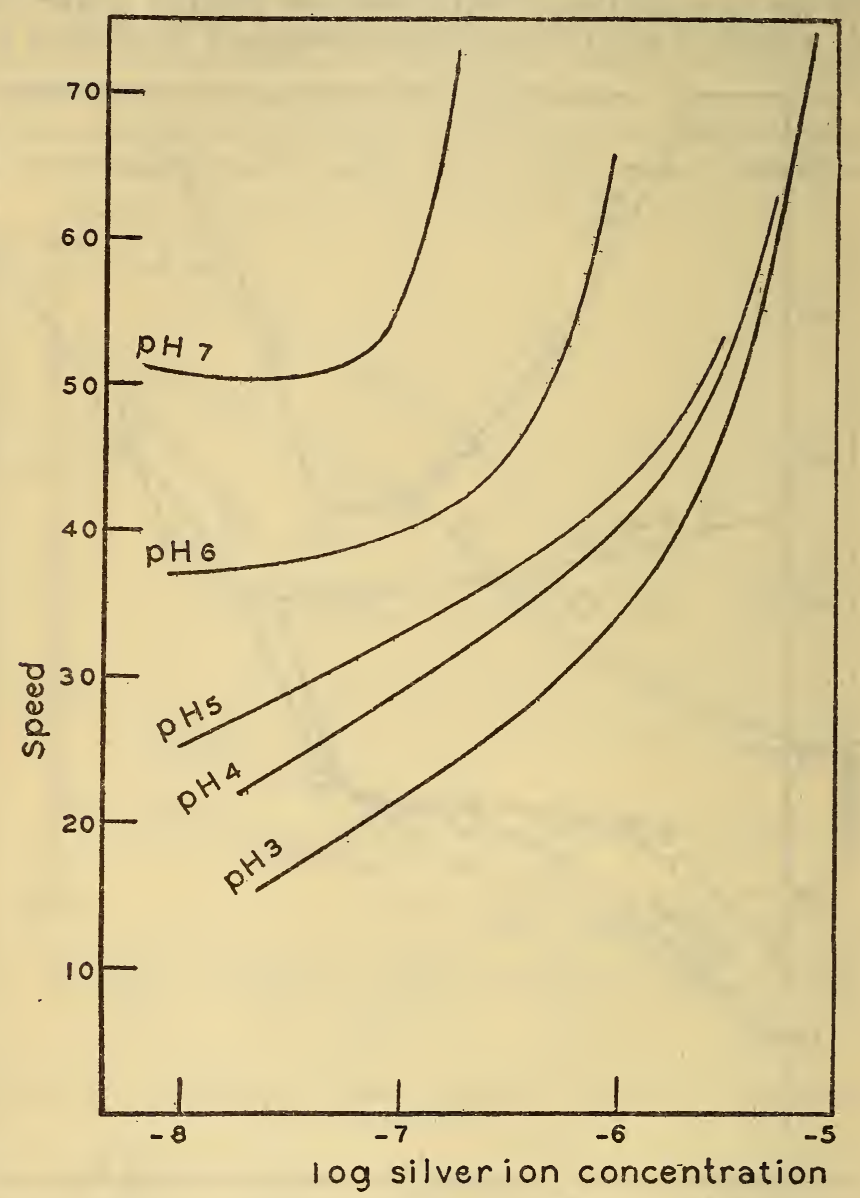

FIGURE 6.-Variation of sensitivity of emulsions with silver ion concentration during digestion, for constant time of digestion

ing silver ion concentration, as is to be expected from the effect of silver ion concentration on after ripening. ${ }^{20}$ (The last two points of the curve for 6-84 are out of place in both Figures 4 and 5, and possibly unreliable.) All four curves have points of inflex ion or minima at pH 5 to 5.5 ; the corresponding characteristic curves have minimum values of $\gamma$ in this region. On the acid side of the isoelectric point the shape of the curves is highly dependent on the silver ion

20 See footnote 3, p. 482 . 
concentration. We have already noted ${ }^{21}$ that on changing the hydrogen ion concentration of an emulsion, the resulting change in silver ion concentration is in the direction which tends to counteract the photographic effect of the original change of $\mathrm{pH}$. Under ordinary conditions, as in emulsion 6-83, the change in silver ion concentration is relatively small and the rate of afterripening increases with $\mathrm{pH}$, although the shape of the curve is decidedly different on the two sides of the isoelectric point. In the emulsions with excess silver (6-84 and 6-85) the silver ion concentration increases so rapidly with decreasing $\mathrm{pH}$ that its effect on the rate of afterripening more than offsets the effect of the acidity, and at $\mathrm{pH}<4.7$ sensitivity actually increases with increasing acidity, under constant time and temperature of digestion. It should be emphasized that in all batches of a given emulsion, as 6-85, the excess of silver over bromine was constant, but its distribution between free and combined ions varied with the $\mathrm{pH}$ with the consequences here indicated.

In Figure 6 the data from the two previous figures have been combined as smoothed curves indicating the change in sensitivity with silver ion concentration at constant values of $\mathrm{pH}$. The original expectation had been that these curves would show a sudden increase in sensitivity when the silver ion concentration exceeded the equivalence point $\left(\left[\mathrm{Ag}^{+}\right]=10^{-6} \mathrm{~N}\right)$. This is roughly the case for emulsions at $\mathrm{pH} 5$ or less, but on the alkaline side of the isoelectric point the point of increase comes at decreasing values of silver ion concentration. It should be remembered that actual equivalence of silver and bromine in the emulsion at normal values of $\mathrm{pH}$ corresponds to silver ion concentration much less than $10^{-6} N$. At pH 7, and concentrations similar to these emulsions, the bromide in solution is equivalent to the silver in combination with the gelatin at $\left[\mathrm{Ag}^{+}\right]=2 \times 10^{-8}\left(\left[\mathrm{Br}_{-}\right]\right.$ $\left.=5 \times 10^{-5}\right)$.

In discussion of these emulsions, no attempt has been made to calculate changes in silver ion concentration from changing acidity, since the emulsions were digested after adjusting the $\mathrm{pH}$. It is further doubtful whether the data in reference 2 are accurate for all samples of gelatin; the available emulsion gelatins appear to vary in their capacity for combination both with silver and hydrogen ions although the qualitative behavior and order of magnitude of the effects is always the same. The measurements of reference 2 were made on de-ashed gelatin which fulfills the tentative specifications ${ }^{22}$ of the American Chemical Society for a standard gelatin as to source and ash content.

\section{ADJUSTMENT AFTER DIGESTION}

(a) SILVER ION CONCENTRATION AT CONSTANT pH

Data in this section were obtained from emulsions which had been digested nearly to maximum sensitivity before adjustment of the silver ion concentration; while we do not feel justified in referring to them as at equilibrium, the rate of change of sensitivity with time was nearly at its lowest point. The emulsions were usually digested at least one hour at $55^{\circ} \mathrm{C}$., then filtered, being cooled to $35^{\circ}$ to $40^{\circ} \mathrm{C}$. in the process. They were then divided into smaller batches, the silver ion concentrations adjusted by appropriate additions of silver 
sulphate or potassium bromide solutions, and the emulsion coated as rapidly as possible. The maximum difference between any of the batches was 15 minutes, which, at a temperature not over $40^{\circ}$, introduced negligible changes in sensitivity; the temperature coefficient of afterripening is such that this interval at $40^{\circ}$ corresponds to less than five minutes at $55^{\circ}$. These data may safely be considered to represent the direct effect of silver ion concentration on sensitivity, rather than the larger indirect effect which is the result of varying silver ion concentration during afterripening. The greatest effect was observed at hydrogen ion concentrations which very greatly retard afterripening.

Figure 7 presents results for a number of emulsions, all of the neutral ("C") type, with $4.0 \mathrm{~mol}$ per cent silver iodide. Speeds

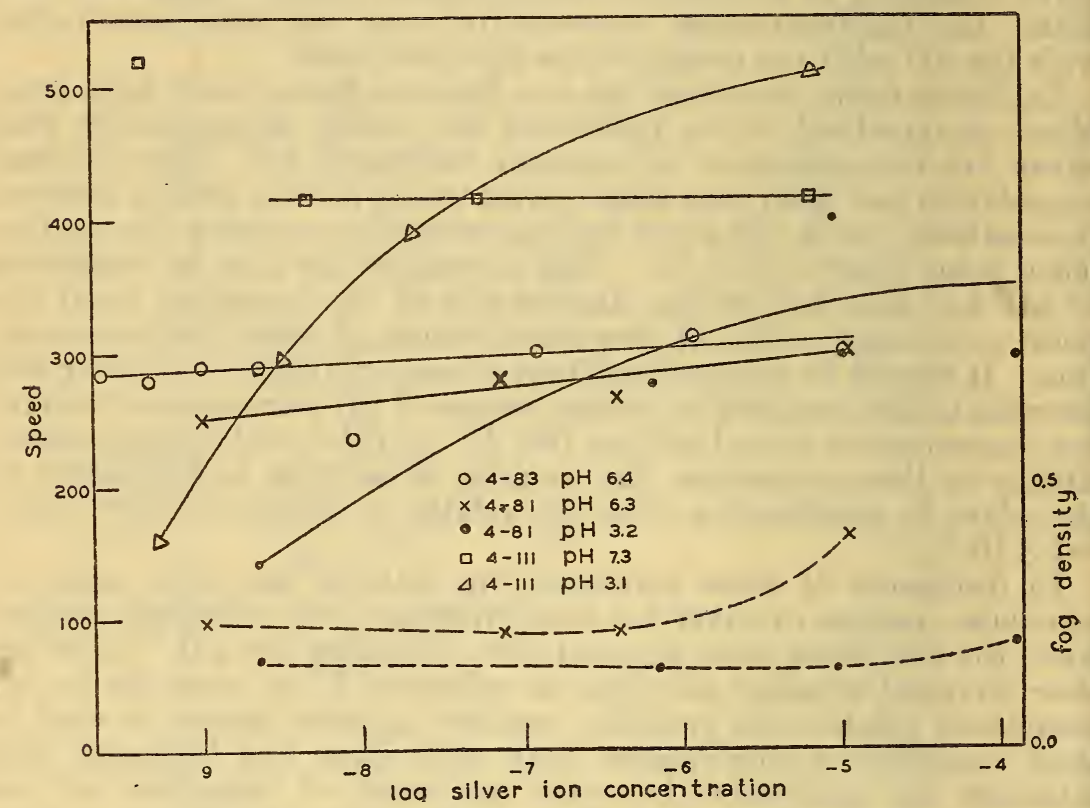

Figure 7.-Variation of sensitivity and fog of emulsions with silver ion concentration at time of coating (after digestion under constant conditions)

Solid lines, speed; dashed lines, fog.

Emulsion 4-83 at pH 6.4 .

$\times$ Emulsion $4-81$ at $\mathrm{pH} 6.3$.

Emulsion $4-81$ at $\mathrm{pH} 3.2$

Emulsion 4-111 at $\mathrm{pH} 7.3$.

$\triangle$ Emulsion 4-111 at $\mathrm{pH} 3.1$.

are derived from inertia values, $\gamma$ being practically constant, except for emulsion 4-81 for which the minimum gradient value was more satisfactory. The normal range of silver ion concentrations in emulsions at coating is between $10^{-7.5}$ and $10^{-9}$. The most striking feature of the data is the practically constant value of speed over an enormous range of silver ion concentration when the emulsions were at normal values of $\mathrm{pH}$.

On the acid side of the isoelectric point the effect of silver ion concentration was much greater. As the figure is plotted on the basis of silver ion concentrations, the excess of silver over halogen at corresponding abscissas was less in the case of the batches on the 
acid side of the isoelectric point, since the silver combined with gelatin was less. The difference between the neutral and acid batches would, therefore, be even greater if the results were presented in terms of excess bromide or silver.

Fog densities for 12-minute development of the different portions of 4-81 are also plotted in Figure 7, using dashed lines and the same symbols for the points as for the plot of speed of the corresponding portions. While there is a sudden increase in fog at the higher silver ion concentrations, not only excess of silver over bromine, but excess of free silver ions failed to produce large values of fog immediately; the batches with excess silver and normal $\mathrm{pH}$ deteriorated very rapidly, while those with excess silver at $\mathrm{pH} 3$ were usable for over a month. The maximum fog in 4-111, made with ammonia-treated gelatin, was 0.06 .

The marked effect of excess silver on the blackening of silver bromide without development, and the extension of spectral sensitivity toward the red reported by Fajans, ${ }^{23}$ have both been studied mainly using silver bromide without protective colloid or protected by collodion, which does not have the capacity of gelatin to combine with silver ions. Tests were accordingly made with three emulsions 4-111, using both the neutral and acid batches, a similar emulsion: (4-110) available both with excess silver and bromide and having only 1 per cent AgI so that the sensitivity did not extend as far to the red as in 4-111, and an ammonia-process emulsion (1-166) with 4 per cent AgI.

The direct blackening was tested simply by exposing strips of corresponding pairs of plates (excess silver and excess bromide) to diffuse daylight, and observing the changes visually. The excess silver produced only a slight increase in the 4-110, and no appreciable difference in the 4-111 in either pair (pH 7.3 and 3.1).

TABLE 2.-Distribution of silver and bromide ions in emulsion 4-81, on adjustment of $\mathrm{pH}$ and $\left[\mathrm{Ag}^{+}\right]$

[Results calculated to 1 liter of emulsion, containing $0.23 \mathrm{~mol} \mathrm{AgBr}$ and $58 \mathrm{~g}$ gelatin]

\begin{tabular}{|c|c|c|c|c|c|}
\hline $\mathrm{pH}$ & Added $\mathrm{Ag}^{+}$or $\mathrm{Br}$ & {$\left[\mathrm{Ag}^{+}\right]$} & Excess in solution & $\begin{array}{c}\mathrm{Ag}^{+} \text {combined with } \\
\text { gelatin }\end{array}$ & $\begin{array}{l}\text { Apparent change } \\
\text { in adsorbed } \mathrm{Br}^{m} \\
\text { per mol } \mathrm{AgBr}\end{array}$ \\
\hline 6.3 & $\left\{\begin{array}{c}g \text { equivalent } \\
1.01 \times 10^{-3} \mathrm{Br}^{-} \\
2.3 \times 10^{-4} \mathrm{Ag}^{+} \\
1.16 \times 10^{-3} \mathrm{Ag}^{+}\end{array}\right.$ & $\begin{array}{c}N \\
7.4 \times 10^{-8} \\
1.05 \times 10^{-8} \\
3.9 \times 10^{-7}-\ldots \\
1.09 \times 10^{-5}\end{array}$ & $\begin{array}{c}\text { gequivalent } \\
1.23 \times 10^{-5} \mathrm{Br}^{-} \\
8.8 \times 10^{-4} \mathrm{Br}^{-} \\
1.8 \times 10^{-6} \mathrm{Br}^{-} \\
1.08 \times 10^{-5} \mathrm{Ag}^{+}\end{array}$ & $\begin{array}{c}g \text { equivalent } \\
1.04 \times 10^{-4} \\
6 \times 10^{-6} \\
3.0 \times 10^{-4} \\
1.45 \times 10^{-3}\end{array}$ & $\begin{array}{l}\quad g \text { equivalent } \\
\text { c. } 1.7 \times 10^{-4} \\
+1.3 \times 10^{-4} \\
-9 \times 10^{-4}\end{array}$ \\
\hline 3.3 & $\left\{\begin{array}{l}0 \\
1.01 \times 10^{-3} \mathrm{Br}^{-} \\
2.3 \times 10^{-4} \mathrm{Ag}^{+} \\
1.16 \times 10^{-3} \mathrm{Ag}^{+} \ldots\end{array}\right.$ & $\begin{array}{l}6.6 \times 10^{-7} \\
2.2 \times 10^{-0}=\ldots \\
8.6 \times 10^{-6}=2 \\
1.22 \times 10^{-4}\end{array}$ & $\begin{array}{l}6 \times 10^{-7} \mathrm{Br}^{-} \\
4.0 \times 10^{-4} \mathrm{Br}^{-} \\
8.5 \times 10^{-6} \mathrm{Ag}^{+} \ldots \\
1.22 \times 10^{-4} \mathrm{Ag}^{+} \ldots\end{array}$ & $\begin{array}{l}3.6 \times 10^{-5} \\
3 \times 10^{-6}-1.7 \times 10^{-4} \\
8.1 \times 10^{-4}\end{array}$ & $\begin{array}{l}0 \\
+25 \times 10^{-4} \\
-2.2 \times 10^{-i} \\
-12 \times 10^{-4}\end{array}$ \\
\hline
\end{tabular}

Spectral sensitivity was tested by exposure to a continuous source in a small grating spectrograph giving high intensity. ${ }^{24}$ A Wratten "minus blue" filter was used to reduce the effect of stray light so that the exposure could be followed to regions of low sensitivity. The plates were brush developed to insure uniformity and measured with a microphotometer. No detectable change in spectral sensitivity 
was produced by the excess silver in any of the sets compared. These same emulsions were also tested for a change in spectral sensitivity with $\mathrm{pH}$, carrying the measurements well to the acid side of the isoelectric point of gelatin. The results were again negative with the possible exception of those batches of 1-166 containing excess silver; in this case the decrease in sensitivity for the longer wave lengths produced by decrease in pH from 7.7 to 3.2 , if real, is of a smaller order of magnitude than the effect of changing from 4 to 1 per cent AgI.

In Table 2 the data are given for the adjustment of silver ion concentration in emulsion 4-81, which was made with the same sample of isoelectric gelatin used for the experiments on silver iongelatin combination. This emulsion was thoroughly washed with tap water, reaching a $\mathrm{pH}$ of 6.3 and $\left[\mathrm{Ag}^{+}\right]$of $7.4 \times 10^{-8} \mathrm{~N}$ as given in the first horizontal row. Half of it was adjusted to $\mathrm{pH} 3.3$ by the addition of sulphuric acid; each half was divided into four batches to which silver sulphate or potassium bromide solutions were added in the indicated quantities. The quantities of free ions in solution and of silver ions combined with the gelatin were calculated from the electrode readings and the data of Figure 3 of reference 2 . The calculation may be illustrated by the figures in the second horizontal row. $1.01 \times 10^{-3} \mathrm{~g}$ equivalent of bromide was added per liter of emulsion. The silver ion concentration, determined directly from the potential of the silver-silver bromide electrode, became $1.05 \times 10^{-9}$; the corresponding bromide ion concentration calculated from the solubility product was $8.8 \times 10^{-4}$. The solution, therefore, contains bromide in excess by $\left(8.8 \times 10^{-4}\right)-\left(1.05 \times 10^{-9}\right)=8.8 \times 10^{-4} \mathrm{~g}$ equivalent per liter. At a pH of 6.3 and silver ion concentration $1.05 \times 10^{-9}$, we find from Figure 3 of reference 2 that $1 \times 10^{-7} \mathrm{~g}$ equivalent of silver ion will combine with $1 \mathrm{~g}$ of gelatin, or $6 \times 10^{-6} \mathrm{~g}$ equivalent with the $58 \mathrm{~g}$ in 1 liter of emulsion. The bromide in solution has, therefore, increased by $\left(8.8 \times 10^{-4}\right)-\left(1.23 \times 10^{-5}\right)=8.7 \times 10^{-4} \mathrm{~g}$ equivalent over the original condition of the emulsion. The silver combined with the gelatin has decreased by $\left(1.04 \times 10^{-4}\right)-\left(6 \times 10^{-6}\right)=0.98 \times 10^{-4} \mathrm{~g}$ equivalent from the original condition of the emulsion. These add up to $9.7 \times 10^{-4} \mathrm{~g}$ equivalent. But $1.01 \times 10^{-3} \mathrm{~g}$ equivalent of bromide was added. The difference is $0.4 \times 10^{-4} \mathrm{~g}$ equivalent of bromide per liter ef emulsion, or $1.7 \times 10^{-4}$ per mol of $\mathrm{AgBr}$, which has apparently been removed by adsorption on the AgBr.

The sum of the changes in these quantities fails to agree with the addition in every case by an amount which is larger than the experimental error. If ascribed to changes in the bromide (or silver) ions adsorbed to the silver halide of the emulsion, the results are of the right sign and order of magnitude. Numerous calculations of this type indicate that approximate values can be obtained for adsorbed bromide, but it is obviously necessary to have data on the combination of silver ion with the gelatin in question to insure reliable results. Data from emulsion 4-83 in the higher bromide ion concentrations, and from emulsions 4-61 and 4-68 (reference 3) both give values for adsorbed bromide which fit the Freundlich equation within the limits of error, but the constants are quite different.

The increased effect of silver ion concentrations in acid emulsions is responsible for a curious effect which we have already mentioned. ${ }^{25}$ 
This effect is further illustrated in Figure 8; the emulsions are described in Table 3. All were made with neutral silver nitrate solution; after mixing and ripening they were centrifuged and the silver halide suspended in dilute gelatin. The silver ion concentration of this suspension was next adjusted by addition of silver sulphate where desired, and it was then divided into portions, the $\mathrm{pH}$ of which was adjusted by sulphuric acid. The resulting range of silver ion concentrations is indicated in Table 3 . These portions of the wash suspension, all containing the same excess silver or bromide and varying only in $\mathrm{pH}$ and the resulting distribution of silver ions, were then centri-

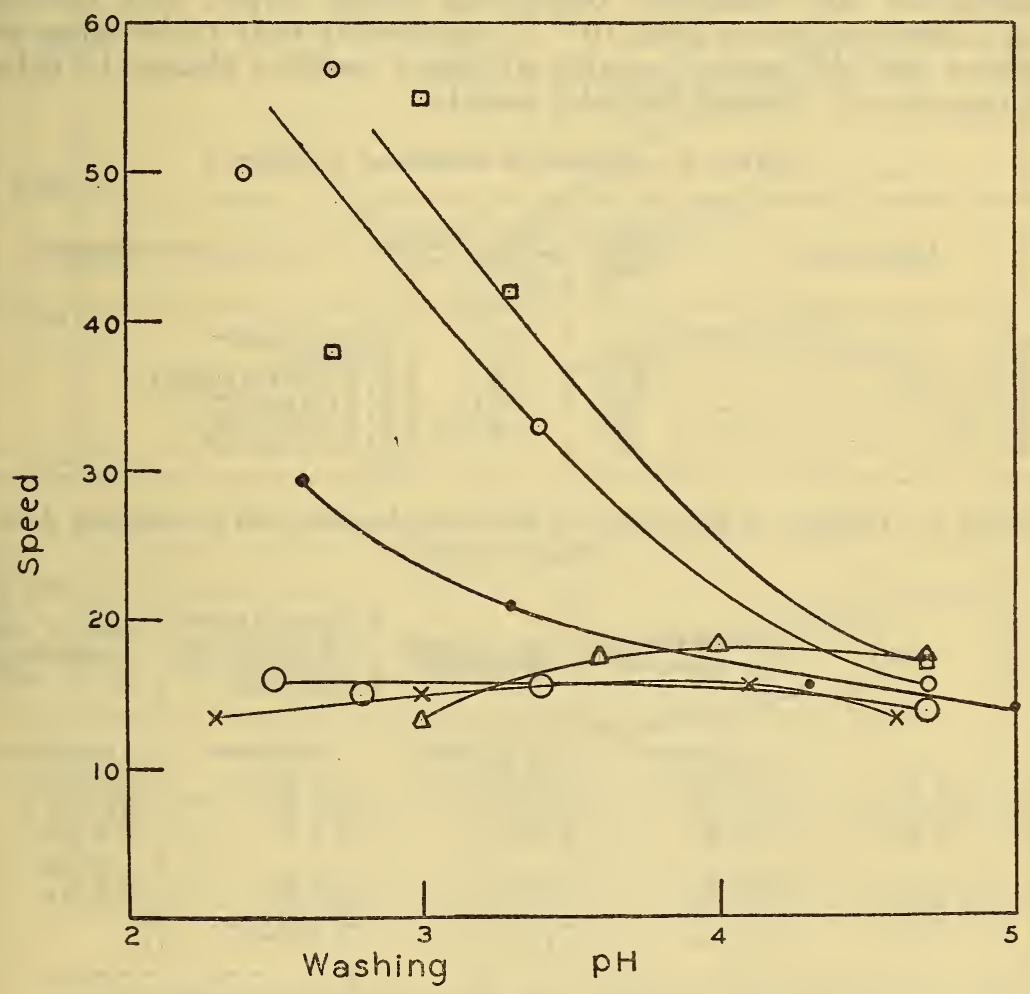

FIGURE 8.-Variation of speed of centrifugally washed emulsions with $p H$ of first resuspension

fuged again and the silver halide suspended in fresh gelatin at constant $\mathrm{pH}$. They were coated without digestion; other experiments showed that the effect tended to diminish on digestion, the after ripening bringing them to a common higher level of sensitivity. Ammonia-treated gelatin was used for the final suspension in all cases, to reduce fog in the emulsions with excess silver.

In the emulsions with excess bromide $(6-80,6-82)$ and in one with a small excess of silver (6-79), there was practically no effect produced by the changing $\mathrm{pH}$ of the wash suspension. In those with excess silver $(6-76,6-77,6-81)$ there was a marked increase in sensitivity with increasing acidity. As the silver ion concentration of the wash suspensions increased with increasing acidity over the 
range given in Table 3, there was a corresponding change in the final suspension, but it amounted to a maximum of 60 per cent, which could not account for the change in sensitivity. It is necessary to assume that a given silver ion concentration sensitizes the silver halide grains by an amount increasing with the acidity, most probably because there is increased adsorption of silver ions. A possible explanation will be discussed later in the paper. Entirely analogous results were obtained with ammonia process emulsions; illustrations are given by the "control" batches in Table 9 of reference 25 . Colloidal silver and gold (reference 25) were found to sensitize only when introduced into emulsions containing excess silver, and hydrogen ion concentrations at least $10^{-3} \mathrm{~N}$; apparently only under these conditions did the grains acquire sufficient positive charge to attract the negatively charged colloidal metals.

TABLE 3.-Emulsions illustrated in Figure 8

\begin{tabular}{|c|c|c|c|c|c|}
\hline Iimulsion No. & $\begin{array}{c}\text { Symbol } \\
\text { in Fig- } \\
\text { ure 8 }\end{array}$ & $\begin{array}{c}\text { Mol } \\
\text { per cent } \\
\text { AgI }\end{array}$ & $\begin{array}{c}\text { Coating } \\
\mathrm{pH}\end{array}$ & {$\left[\mathrm{Ag}^{+}\right]$in wash su } & uspension \\
\hline 6 & $\begin{array}{l}\text { (.) } \\
\text { (O) } \\
\left(\mathrm{O}^{\prime}\right) \\
(\mathrm{X}) \\
(\Delta)\end{array}$ & $\begin{array}{r}0.0 \\
.0 \\
.0 \\
2.3 \\
.0 \\
.0\end{array}$ & \begin{tabular}{l|}
3.4 \\
3.4 \\
3.4 \\
3.4 \\
3.4 \\
8.2
\end{tabular} & $\begin{array}{l}1.4 \text { to } 1.6 \times 10^{-3} \text {. } \\
6 \times 10^{-4} \\
4.7 \times 10^{-0} \text { to } 4.4 \times 10^{-5} \text {. } \\
3.1 \text { to } 3.5 \times 10^{-10} \\
3.4 \text { to } 4.6 \times 10^{-i} \text {. } \\
3.5 \text { to } 4.2 \times 10^{-9} \text {. }\end{array}$ & \\
\hline
\end{tabular}

TABLE 4.-Changes in distribution of silver and bromide ions in emulsion 4-80 on adjusting $p H$

\begin{tabular}{|c|c|c|c|c|c|}
\hline $\mathrm{pH}$ & {$\left[\mathrm{Ag}^{+}\right]$} & $\begin{array}{l}\text { Excess of } \mathrm{Br} \text { - over } \\
\mathrm{Ag}^{+} \text {in solution }\end{array}$ & $\begin{array}{l}\mathrm{Ag}^{+} \text {combined } \\
\text { with gelatin }\end{array}$ & $\begin{array}{l}\text { Excess of } \mathrm{Ag}^{+} \text {over } \\
\mathrm{Br} \text {-in emulsion, } \\
\text { excluding ad- } \\
\text { sorbed } \mathrm{Br} \text { - }\end{array}$ & $\begin{array}{c}\text { A pparent change } \\
\text { in adsorbed } \mathrm{Br} \text {, } \\
\text { per mol } \mathrm{AgBr}\end{array}$ \\
\hline $\begin{array}{l}8.7 \\
6.4 \\
5.4 \\
4.9\end{array}$ & $\begin{array}{l}1.8 \times 10^{-8} \\
8.3 \times 10^{-8} \\
1.5 \times 10^{-7} \\
2.2 \times 10^{-7}\end{array}$ & 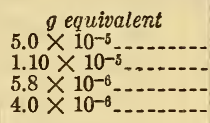 & $\begin{array}{l}\quad \text { gequivalent } \\
1.8 \times 10^{-4}-\ldots \\
1.1 \times 10^{-4}- \\
5 \times 10 \\
4 \times 10^{-5}- \\
\end{array}$ & $\begin{array}{l}\quad \text { gequivalent } \\
1.3 \times 10^{-4}-1 \\
1.0 \times 10^{-4} \\
4.9 \times 10^{-5} \\
3.6 \times 10^{-5}\end{array}$ & $\begin{aligned} & \text { gequivalent } \\
+ & 4.4 \times 10^{-4} \\
+ & 3.2 \times 10^{-4} \\
+1.0 \times 10^{-4} & \\
+ & 5 \times 10^{-5}\end{aligned}$ \\
\hline $\begin{array}{l}4.5 \\
4.1 \\
3.4 \\
2.2\end{array}$ & $\begin{array}{l}3.3 \times 10^{-7} \\
4.2 \times 10^{-7} \\
5.0 \times 10^{-7} \\
6.4 \times 10^{-7}\end{array}$ & $\begin{array}{l}2.5 \times 10^{-6}- \\
1.8 \times 10^{-6} \\
1.35 \times 10^{-5} \\
7.9 \times 10^{-7}\end{array}$ & $\begin{array}{l}3.5 \times 10^{-5}- \\
3 \times 10^{-5}- \\
2.5 \times 10^{-5}- \\
2.5 \times 10^{-5}-\end{array}$ & $\begin{array}{l}3.2 \times 10^{-5} \\
2.8 \times 10^{-5} \\
2.4 \times 10^{-5} \\
2.4 \times 10^{-5} \\
\end{array}$ & $\begin{array}{l}+3 \times 10^{-5} \\
+2 \times 10^{-5} \\
0 . \\
0 .\end{array}$ \\
\hline
\end{tabular}

All results calculated to 1 liter of emulsion, which contained $0.24 \mathrm{~mol} \mathrm{AgBr}$ and $60 \mathrm{~g}$ dry gelatin.

\section{(b) HYDROGEN ION CONCENTRATION}

Silver ion concentrations may readily be adjusted at constant $\mathrm{pH}$, since small amounts of practically neutral salts may be used, but as already pointed out, change in hydrogen ion concentration involves a change in silver combined with gelatin and, therefore, a change in silver ion concentration. The smaller the amount of soluble bromide present in the emulsion the larger will be the change, both in relative and absolute units. Table 4 gives the results of changing the $\mathrm{pH}$ in an emulsion made with the standard de-ashed gelatin used for investigation of the silver ion-gelatin combination. This emulsion was thoroughly washed (six hours in running tap water) and contained only a very small excess of total halogen over silver. Changes in distribution of silver and bromide on changing $\mathrm{pH}$ have been calcu- 
lated from the electrode readings and the data of Figure 3 of reference 2 ; values for adsorbed bromide are again only relative, the absolute amount being unknown. The change in adsorbed bromide is about what would be expected from the change in bromide ion concentration; the evidence is not sufficient to decide whether there is any effect of $\mathrm{pH}$ on the adsorption.

We have already ${ }^{26}$ called attention to the fact that the change in silver ion concentration tends to oppose the direct effect of changing $\mathrm{pH}$. When there is no subsequent afterripening, as in this case, the

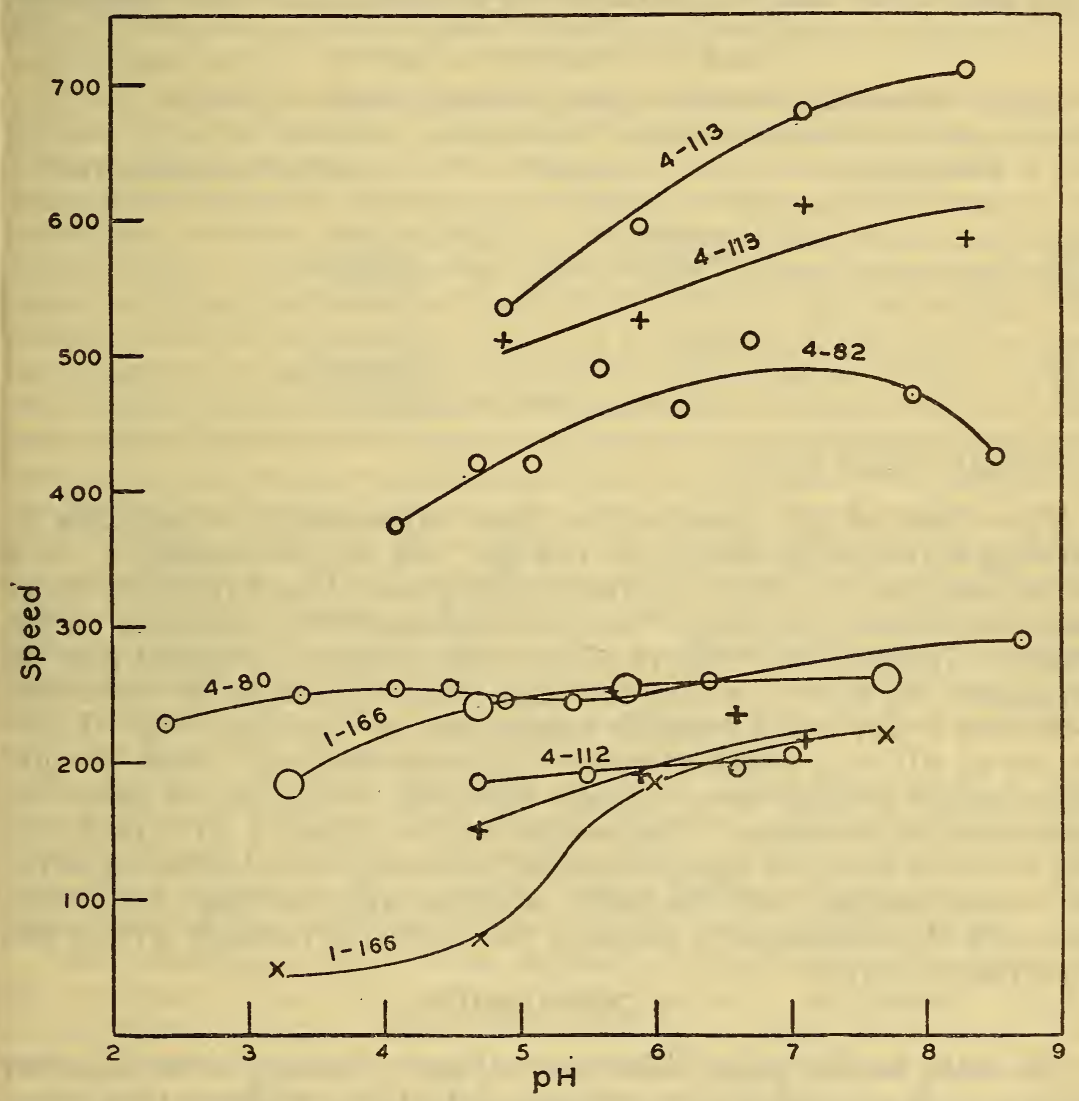

FIGURE 9.-Variation of speed of emulsions with pH at time of coating (after digestion)

change in silver ion concentration becomes relatively unimportant. In a thoroughly washed emulsion, such as 4-80, the silver ion concentration may change tenfold between $\mathrm{pH} 8.3$ and 4.9. If, on the other hand, the emulsion contains about 1 per cent soluble bromide $\left(\left[\mathrm{Ag}^{+}\right]\right.$ approximately $10^{-9} \mathrm{~N}$ ) the change in silver ion concentration may be as low as 20 per cent between the same limits of $\mathrm{pH}$; as may be judged from inspection of Figure 7, this is quite negligible.

Figure 9 presents the results of changing $\mathrm{pH}$ of a number of emulsions just before coating. Three of the emulsions were divided in half, 
and the silver ion concentration of each half adjusted before adjusting the $\mathrm{pH}$. Most of the data are for thoroughly washed emulsions (indicated by circles), but three sets (indicated by crosses) are for emulsions containing about 1 per cent soluble bromide. The emulsions are described more fully in Table 5. The inertia of some of these emulsions tended to vary appreciably with the degree of development. Since the rate of development varied with the emulsion $\mathrm{pH}$, as would be expected, the speeds are those for development to a constant value of $\gamma$ (1.0 for emulsions $4-112$ and $4-113$ and $1-166 ; 1.5$ for emulsions 4-80 and 4-82); this was obtained by interpolation where necessary.

\section{TABLE 5.-Emulsions in Figure 9}

Emulsion 1-166 was made by the ammonia process, the others by the neutral (C) formula.

\begin{tabular}{|c|c|c|}
\hline Emulsion No. & Gelatin & {$\left[\mathrm{Ag}^{+}\right]$before adjustment of $\mathrm{pH}$} \\
\hline $4-80$ & $\begin{array}{l}\text { De-ashed } \\
\text { Winterthur. }\end{array}$ & $\begin{array}{l}8.3 \times 10^{-8} \\
6.7 \times 10^{-8}\end{array}$ \\
\hline $4-112 \ldots$ & _._. do _ _ _ & $\left\{\begin{array}{l}7.7 \times 10^{-8} \\
17.0 \times 10^{-10}\end{array}\right.$ \\
\hline $4-113$ & Ucopco _. & $\left\{\begin{array}{l}1.5 \times 10^{-7} \\
17.5 \times 10^{-10}\end{array}\right.$ \\
\hline $1-166$ & -..--do do & $\left\{\begin{array}{l}18.3 \times 10^{-10} \\
3.7 \times 10^{-6}\end{array}\right.$ \\
\hline
\end{tabular}

1 Indicated by crosses in Figure 11.

The effect of $\mathrm{pH}$ observed in these experiments corresponds to Rawling's reversible effect; we did not test for reversibility. It is much less than the effect on after-ripening and almost vanishes under some conditions. Rawling ${ }^{27}$ has demonstrated its dependence on the gelatin. Inspection of Figure 7 shows the extent to which it may be dependent on silver ion concentration, since the data for emulsions 4-81 and 4-111 make possible comparison of the sensitivity at two values of $\mathrm{pH}$ and constant silver ion concentration. Here the $\mathrm{pH}$ effect passes through zero, actually changing its sign as the silver ion concentration increases. The results with emulsions 4-112 and 1-166 (fig. 9) are of the same type, the effect increasing with decreasing silver ion concentration, but the order is apparently reversed for 4-113, although the difference in slope of the curves is possibly within the experimental error.

\section{DISCUSSION}

The data in this paper, like those of our previous communication (reference 3), are uniformly consistent with the hypothesis that afterripening is the result of chemical reactions of the silver halide to form silver sulphide or possibly metallic silver. Such reactions must lead to the formation of acid and of halide ions, and should, therefore, be retarded by increase in bromide or hydrogen ion concentrations. This was found experimentally in every case. There is an apparent contradiction in the decrease of sensitivity in the emulsions with $\mathrm{pH}>8$, but it will be noted that the velocity of the change continued to increase, the maximum of sensitivity being reached in less time than for lower values of $\mathrm{pH}$. The available evidence indicates that the quantity of silver sulphide is not the only variable in the effectiveness of a nucleus, so that photographic sensitivity might begin to fall off 
even though the process of forming silver sulphide was not retarded. The effects of hydrogen and silver ion concentrations during digestion are thus as accountable as any features of the after-ripening process.

The effect of environment $\mathrm{pH}$ is apparently independent of previous afterripening, since Rawling found it to be independent of the presence of nuclei formed by known additions of allyl thiocarbamide. It must be explained by hypotheses which do not involve changes in the nucleation of the grains. We have an analogous case in the mechanism of spectral sensitization, since Sheppard ${ }^{28}$ found that the relative spectral sensitivity of a given emulsion-dye combination was not affected by addition or removal of nuclei which produced great changes in the total sensitivity.

It will be useful first to consider the nature of the adsorption of gelatin to silver bromide. Reinders ${ }^{29}$ demonstrated that the adsorption of gelatin reduces the adsorption of other materials, but it has been tacitly assumed in many cases that the adsorption of ions and of protective colloids had distinct mechanisms and were relatively independent. According to the "Zwitterion" theory of ampholytes, ${ }^{30}$ however, gelatin is considered to be very largely in the ionic state, even though most of the ions (or micelles) are externally neutral because they carry an equal number of positive and negative charges. Such zwitterions should be capable of oriented polar adsorption to a crystal lattice like silver bromide; assuming the existence of amino acid groups the gelatin zwitterion would be adsorbed to silver ions of the surface by electrostatic attraction between $\mathrm{Ag}^{+}$and $-\mathrm{COO}^{-}$, and to the bromide ions by their attraction for $-\mathrm{NH}^{+}$. Undissociated molecules would not be adsorbed. The externally charged ions of the earlier theory, which exist in increasing proportions as the $\mathrm{pH}$ departs from the isoelectric point in either direction, would be adsorbed only to the corresponding ions of the silver bromide surface. In every case, adsorption of the gelatin should be polar, and competitive with the adsorption of other ions, even those of silver bromide itself.

It seems reasonable that this type of adsorption explains the superiority of the proteins over un-ionized colloids as protective colloids for silver bromide, expecially with regard to protection of the unexposed silver bromide against development if we assume that adsorption of the developer ion is the first step in that process.

The zwitterion concept also implies a relatively rapid change in the number of free $\mathrm{NH}_{2}$ groups with the $\mathrm{pH}$. As pointed out by Slater Price, this may effect the reactivity of the gelatin with bromine. It also appears to explain the marked dependence of the silver ion-gelatin combination on $\mathrm{pH}$, assuming this to take place at the amino group, much better than the opening of peptide linkages which are assumed in our previous discussion of this subject ${ }^{31}$ or the structural changes suggested by Sheppard (reference 13).

We believe that our results may best be explained on the assumption that gelatin is adsorbed to silver halides in preference to all other materials present. Only the bromide ion (which is adsorbed more strongly than the silver ion) will also be appreciably adsorbed, especially in acid solutions where the acid dissociation of the gelatin is reduced so that the $-\mathrm{COO}^{-}$ion groups are less available for

${ }^{28}$ Sheppard, Colloid Symposium Monograph, vol. 3, p. 3.

29 Reinders, Zeit. f. phys. Chem., vol. 77, p. 677, 1911.

30 Bjerrum, Zeit. f. phys. Chem., vol. 104, p. 147, 1923.

a1 See footnote 2, p. 482 . 
adsorption to the $\mathrm{Ag}^{+}$ions of the crystal lattice. Our data in agreement with the work of Slater Price and his associates show that the effect of hydrogen ion concentration on sensitivity is greater at higher bromide ion concentrations. As is evident from Figure 7, this may better be expressed that at low values of $\mathrm{pH}$, bromide has an increased desensitizing effect. It has already been mentioned that under these conditions it should be more capable of displacing adsorbed gelatin, with consequent desensitization. Silver ions will, in general, be adsorbed in appreciable quantity only at relatively high concentrations. (It will be remembered that the silver ion concentration in an emulsion at normal values of $\mathrm{pH}$ exceeds the bromide ion concentration only when the emulsion contains about 0.4 per cent excess silver.) Our most direct evidence for this is the independence of the spectral sensitivity of the silver and hydrogen ion concentration. There was no indication that even the considerable excess of silver present in some of the emulsions caused an increase in sensitivity to the longer wave lengths. There is, furthermore, evidence that the adsorption of the gelatin causes such a shift, since the sensitivity of pure silver bromide in gelatin has its maximum at about 450 $\mathrm{m} \mu$ as against $420 \mathrm{~m} \mu$ for silver bromide collodion ${ }^{32}$; Eder's sensitivity curves show an unmistakable shift of the whole curve to the red in the presence of gelatin. It is therefore probable that in the grains of a silver bromide-gelatin emulsion the deformation of the external bromide ions of the crystal lattice is already accomplished so that it is unaffected by silver or hydroxyl ions at moderate concentrations.

The effect of excess silver on the sensitivity of gelatin emulsions has been found to be unexpectedly small in view of its marked effect under other conditions, such as the photolysis of medium-free silver bromide. The most important factor is the combination of gelatin with silver ions, which retards the increase of silver ion concentration when soluble silver salts are added to an emulsion, and prevents the formation of the "silberkorper" of Fajan's experiments. There is a further influence to be considered. In the photolysis of medium-free silver bromide excess silver increases the rate of reaction under constant illumination by a factor of several times, although the increase in absorption of light can be detected only by careful measurement. This result can not be explained wholly by the change in the primary photochemical process; the silver must also influence secondary reactions, probably by acting as a bromine absorbent. Some bromine absorbent is essential to prevent regression in the photolysis of pure silver bromide. In the emulsion, the case is quite different, and an absorbent as inefficient as a silver salt does not add to sensitivity. The evidence indicates that some more effective material is normally present, and that the effects of such variables as hydrogen ion concentration are to be explained in terms of some secondary reaction, probably connected with the bromine liberated during exposure.

This is the basic hypothesis used by Slater Price ${ }^{33}$ to explain the effect of $\mathrm{pH}$ on sensitivity. We fully agree with him that the photochemical reaction leading to the latent image, like practically every other photochemical reaction which has been studied, involves a primary process which is the direct consequence of the absorption of

${ }^{32}$ Vogel, Eder's Ausführliches Handbuch der Photographie, vol. 3, p. 143, 5th ed., 1903. Eder, Handbuch, vol. 2, Figure 162, p. 377; 1st ed., 1897.

33 See footnote 10, p. 484. 
light, and subsequent secondary reaction or reactions which are purely chemical in nature. The secondary reactions are subject to the same influences as other chemical reactions, and consequently the total chemical reaction associated with a given primary absorption may be widely modified by changing conditions such as the pH. There have been statements that in the photograpbic emulsion the primary and secondary reactions are the formation of the latent image and development, respectively. While this statement may be a useful analogy in the discussion of photochemistry, it is pure assumption that the formation of the latent image involves only the primary process; there is no evidence that such is the case. A priori it is highly improbable that in a system as complicated as the photographic emulsion there are no secondary reactions, and the existence of the intermittency and reciprocity effects are strong evidence that the secondary reactions do occur. The quantum theory of photochemical reactions implies that the primary process is the necessary consequence of the absorption of a quantum of the proper frequency; a change in the quantum yield with constant absorption, as in exposures at different intensities, must, therefore, be ascribed to secondary reaction.

The shift in spectral sensitivity observed by Fajans involves the primary process, since a smaller quantum has become effective. In contrast to this, the increase in atoms of silver liberated, over and above the increased quantum absorption, must mean a change in the secondary reactions-decreased regression, for example.

While the existence of secondary reactions in latent image formation is practically necessary in the light of general photochemistry, there is no direct evidence of their chemical nature. Slater Price adopts the most obvious chemical theory-that the secondary reactions are connected with the disposal of the bromine liberated by photolysis of silver bromide. In some form or other this theory has been used since the earliest days of gelatin emulsions to explain their superior sensitivity. The gravest objection to it is the general failure of halogen absorbents to act as photographic sensitizers in gelatin emulsions. Materials such as thioanilides ${ }^{34}$ and sulphites, ${ }^{35}$ even though they are halogen absorbents and may be adsorbed to silver bromide so as to be in the most favorable position for reaction with the bromine, are found to be desensitizers. However, they greatly accelerate the visible photolysis of silver bromide, and delay or prevent solarization. It is, therefore, necessary to assume that silver bromide-gelatin emulsions normally contain something which as an absorbent for the very small quantities of bromine which are liberated in the formation of latent image corresponding to a working density is more efficient than any of the materials which may be added. It must be present only in minute amounts or have only a small capacity, because it can be supplemented by other halogen absorbents for the longer exposures corresponding to solarization and direct blackening. Slater Price believed this to be the gelatin, and demonstrated the parallel between the effect of varying hydrogen ion concentration on the reactivity of bromine and gelatin on the one hand and the sensitivity on the other. The capacity factor just mentioned was not discussed, but it might have been explained by assuming that only 
the gelatin in immediate contact with the grain can react rapidly enough to be effective.

Admitting the existence of an efficient bromine absorbent in silver bromide-gelatine emulsions, we believe that consideration of all the evidence favors Hickman's ${ }^{36}$ hypothesis that it is silver sulphide. It does not seem necessary to accept Hickman's further hypothesis that the reaction leads to increased liberation of metallic silver; it is sufficient if we assume that it merely prevents regression, since the quantum yield for the photolysis of silver bromide in photographic emulsions is more probably less than one, rather than greater than one. The silver sulphide is present in quantities of the right order of magnitude to correspond to the capacity observed. On the hypothesis that the silver sulphide nuclei orient ${ }^{37}$ the photolysis of the silver bromide, they may become preferred bromine absorbents merely by virtue of position, and the orientation hypothesis may be retained even though the latent image is explained in terms of structure of photolytic silver rather than quantity.

The behavior of highly disperse (Lippman type) emulsions offers an apparently crucial distinction between gelatin and silver sulphide as bromine absorbents. The silver bromide of these emulsions has a maximum specific surface for adsorption of gelatin. They have had a minimum of ripening and, therefore, contain a minimum of silver sulphide. Iüppo-Cramer ${ }^{38}$ has furnished quantitative data showing that in these emulsions, unlike ordinary types, the developable sensitivity may be increased by halogen absorbents, such as nitrite and bisulphite. This indicates that the normal bromine absorbent is absent, so that the silver sulphide rather than the gelatin must normally have this function.

It is probable that atomic bromine reacts directly with silver sulphide, if at all; the calculations of Lambert and Wightman ${ }^{39}$ indicate that this gives a larger decrease of free energy than if water is involved, as well as being more rapid. However, if we assume that the reaction involves water, the effect of hydrogen ion concentration may still be explained by its effect on the hypobromous acid equilibrium, as calculated by Slater Price. Otherwise, as the reaction between atomic bromine and silver sulphide would not be directly affected by hydrogen ion concentration, there could only be an indirect effect through reaction of gelatin with the by-products of the first reaction.

This discussion has been based on the commonly accepted theory that the latent image is the result of the photolysis of silver bromide. Weigert ${ }^{40}$ has recently advanced a "micellar" theory of the latent image which is receiving serious consideration because it is based on his important contributions to the photographic effects of polarized light. He postulates that the latent image is the primary product of the absorption of several quanta by a micelle of silver or silver sulphide, the micelle being raised to a higher energy level which is stable until the energy is used to activate the developer. Regression and such phenomena as the intermittency and reciprocity effects are explained by a secondary reaction, the "inner development" of the

${ }^{36}$ Hickman, Phot. J., vol. 67, p. 34, 1927.

${ }_{37}$ Sheppard, Trivelli and Loveland, J. Franklin Inst., vol. 200, p. 51, 1925.

38 Lüppo-Cramer, Zeit. f. wiss. Phot., vol. 30, p. 201, 1931; and earlier articles.

30 Lambert and Wightman, J. Phys. Chem., vol. 31, p. 1249, 1927.

$\$ 0$ Weigart, Zeit. f. Wiss. Phot., vol. 29, p. 191, 1930. 
micelle by the medium, whereby the energy is lost and no longer available to start development. The secondary reaction being exclusively a regression effect, increase in $\mathrm{pH}$, which would tend to increase the reduction potential of the gelatin and the tendency to inner development should decrease rather than increase sensitivity. The effect of silver ion concentration would be difficult to predict.

We conclude that under normal conditions in the photographic emulsion the adsorption of gelatin to the silver bromide grains is such as to reduce the adsorption of other materials and their consequent effects on sensitivity. Replacement of adsorbed gelatin by bromide ions, which causes desensitization, is favored not only by increased bromide ion concentration, but also by increased hydrogen ion concentration. All effects of environment on photographic sensitivity which do not involve changes in absorption of light must be explained in terms of secondary reactions in latent image formation. The most obvious of these secondary reactions, the elimination of bromine, is better explained by reaction with silver sulphide rather than with gelatin.

\section{Acknowledgment}

In the making and testing of the emulsions described in this paper C. M. Kretchman rendered valuable assistance.

Washington, February 15, 1932. 